\title{
Relação e norma na vida do direito
}

\author{
Ruy Cirne Lima \\ Professor catedrático da Faculdade de \\ Direito de Pôrto Alegre, Universidade do \\ Rio Granđe do Sul.
}

A ontologia jurídica, no que tem de específico, é uma ontologia da relação. As demais categorias do ser, a ontologia jurídica as recebe da metafisica geral, sem ajuntar-lhes notação especificadora. À relação, também recebida, como noção comum, da metafísica, acrescenta-se, porém, e a ela sómente, a qualificação "per accidens", que a singulariza como relação jurídica.

\section{I}

A ontologia da relação é essencialmente a ontologia da ordem. Entre os dois aspectos da relação real, o da inerência ("esse in") e o do relacionamento, ou ordenamento ("esse $a d$ "), o aspecto fundamental é pertinente à ordem.

A ordem não é, entretanto, entidade que se super-ajunte às entidades ordenadas; se o fosse, seria uma entidade a mais, a ser, também, ordenada (1). SAnto Tomás advertiu, a propósito: "embora o "ad aliquid" não signifique alguma cousa como inerente, é fôrça que seja

(1) A. D. Sertillanges, La Philosophie de Saint Thomas d'Aquin, 2.a ed., Paris 1940, t. I. p. 103. 
inerente" (2); e acrescentou: "na relação é alguma cousa inerente, embora não por isso mesmo que é relação; assim, também, a ação por isso que é ação, é considerada como do agente; enquanto, porém, é acidente, e considerada como no sujeito agente" (3).

Pelo aspecto da ordem, a relação manifesta-se, decerto", "quasi in aliud transiens et quodammodo rei relatae assistens" (4), como a tocar o ser relacionado, "quodammodo contingentem ipsam rem relatam, prout $a b$ ea tendit in alterum" (5). Mas essa é a aparência, tão só. A ordem consiste, precisamente, na coaptação dos extremos, sem que nada, entre êles, se interponha.

Não se interpõe, de feito, a ordem entre os seres correlatos. Sobrepõe-se-lhes, sim o princípio de ordem, segundo o qual se ordenam eles, um ao outro (6). A operação dêsse princípio, da qual resulta a coaptação perfeita dos correlativos entre si, é tôda a realidade da relação, enquanto ordem.

A coaptação supõe adaptabilidade recíproca dos extremos; a relação, portanto, está, também, nos extremos, por êsse aspecto, que é o aspecto da inerência ("esse in"). Mas a coaptação mesma ("relatio") é efeito da operação de um princípio exterior: o princípio de ordem (7).

(2) De Potent, ч. 8, art. 2, c.:". licet " $\alpha d$ aliquid" non significet ut inhaerens, tamen oportet ut sit inhaerens".

(3) De Potent, q. 7, art. 9, ad VII:"et ita relatio est aliquid inhaerens, licet non ex hoc ipso quod est relatio; sicut et actio ex hoc quod estactio, consideratur ut ab agente; in quantum vero est accidens, consideratur ut in subjecto agente".

(4) S. TH., $D_{e}$ Potent, q. 7, art. 9, ad VII

(5) S. TH., Sum. Theol., I, q. 28, art. 2, c.

(6) S. TH., De Verit., q. 5, art. 3, c.: "quantumcumque... multitudinem invenimus ordinatam and invicem, oportel eam ordinari ad exterius principium".

(7) S. TH., De Verti., q. 5, art. I, ad. IX: “ordo autem ad finem est fini propinquior quam ordo partium ad invicem, et "quodammodo causa eius". 
Há uma ordem no universo, um tecido de relações que se articulam em unidade, segundo a sua causa primeira e a sua finalidade última (8). Nessa ordem, a ordem jurídica se insere; nêsse tecido de relações, a relação jurídica. A valorização moral da finalidade, na ordem jurídica, não lhe destrói, na verdade, a realidade ontológica: especifica-a.

Aceitando a ordem moral e jurídica, e submetendo-se a ela, racional e voluntáriamente, o homem não desnatura nem aniquila as exigências ontológicas que, naquela ordem. se traduzem: obedece-lhes, simplesmente, segundo a sua própria condição ontológica, isto è, enquanto ser dotado de razão e de vontade (9).

Os valores morais, de resto, não se podem dizer exteriores ao homem. Santo Tomás sinalou, concisamente: "unicuique rationali creature inest naturalis inclinatio ad id quod est consonum legi aeternae” (10). A justiça não é um ditame, dado à razão, ou uma regra posta à vontade: é "um impulso espontâneo do ser humano, ao encontro de um fim que lhe é o seu bem" (11).

(8) S. THos. De Potent. q. 7, art. 9. c: "omnes autem creaturae ordinantur ad Deum, et sicut ad principium et sicut ad finern, nam ordo qui est partium universi ad invicem, est per ordinem qui est totius universi ad Deum; sicut ordo qui est inter partes exercitus, est propter ordinem exercitus ad ducem.

(9) A. D. Sertillanges, oib. cit., t. II, p. 234: "Tout le monde comprend que la loi d'un être ne peut pas se retourner contre lui, et que, pour le respecter, elle doit le prendre tel que la réalité la lui donne".

(10) A. D. Sertillanges, La Philosophie des Lois, Paris, 1946, p. 49: “II s'agit d'un principe normatif réglant um dynamisme initial de notre nature. D'une pousée spontanée de l'être humain vers une fin qui est son bien.."

(11) THoN, Rechtsnorm und subjektives Recht, Weimar, 1878, p. 158 
A realidade da valorização moral, na relação jurídica, recebe expressão objetiva, - "extra animam", como Santo Tomás diria, - através do fato jurídico.

Fato jurídico é o fato social, mediante o qual a ordem, segundo a justiça, ou, mais singelamente, a relação jurídica se estabelece e mantém. O fato jurídico não é, pois, um acontecimento instantâneo, um evento efêmero, do qual a relação jurídica decorra como estado perma-. nente. Ao contrário, o fato jurídico é, precisamente, êsse estado duradouro que, condicionando a existência e a vigência da relação jurídica, lhe confere, a esta, a aparência de um estado permanente.

A relação, sim, é instantânea, renovando-se, "singulis momentis", enquanto perduram as condições de sua vigência. Supõe a relação simultaneidade, e a simultaneidade é instantânea, embora possa repetir-se, indefinidamente, "singulis momentis", tanto que perdurem as condições de coexistência, a que se aplique.

Fato jurídico não é, portanto, o contrato, de conclusão instantânea; mas, os contratantes, o objeto do contrato, o contrato mesmo, e a própria coletividade social, a que aquêles pertencem. $O$ todo condicionará a relação jurídica que, graças a essa conjunção, virá a surgir e a perdurar, renovada de instante a instante.

A relação jurídica, não há duvidar, reclama como condição a pluralidade social. Robinso Crusoe, solitário em sua ilha deserta, não é, senão virtualmente, sujeito de relações jurídicas, salvo para com Deus. Dentro na coletividade social, assim a relação entre o sujeito e uma cousa corpórea, como a relação entre o sujeito e a ação ou a abstenção de outro sujeito, definem-se como relações jurídicas, exatamente por se constituirem em face de outros sujeitos ou, melhor dito, com exclusão de outros sujeitos, individuos da mesma coletividade. 
Essa exclusão, evidentemente, não é tão só uma consequência do princípio de identidade, radicada exclusivamente no plano ontológico; é um dado moral, corolário do princípio fundamental de justiça, que prescreve se atribua a cada qual o que é seu, - "suum cuique tribuere". A todos incumbe o dever moral e jurídico de respeitar a atribuição, resultante da relação juridica, pelo qual o termo desta se vincula, como próprio, a um sujeito determinado (11). Insito êsse dever na noção de fato jurídico, à base de toda e qualquer relação jurídica, não há como distinguir, por êsse aspecto, as relações jurídicas, ditas reais, tendo como termo uma cousa corpórea, das relações jurídicas, ditas obrigacionais, tendo como termo a ação ou a abstenção de outro sujeito. O que permite distinguí-las entre si, é, antes, a perseidade ("perseitas") do termo, característica da cousa corpórea ("suppositum"), e estranha às ações $\mathrm{e}$ abstenções de outros sujeitos que, longe de existirem "per se", daqueles dependem para virem a manifestar-se "in actu". A perseidade do termo, nas relações, ditas reais, ou, melhor, a suficiência ontológica daquele explica, de resto, o predomínio crescente, no comércio jurídico, das relações reais sôbre as obrigacionais, - a assim chamada invasão do Direito das Obrigações pelo Direito das Cousas (12).

A coletividade social, dentro na qual a relação jurídica se constitui, é, à sua vez, suscetível de gradação, descendo sucessivamente do humano ao doméstico. De vez. que o sujeito da relação jurídica é, por excelência, o homem, a coletividade social, a seu turno, em que o homem, simplesmente como homem, se inclui, há de ser, primáriamente, a sociedade universal de todos os homens. A mais ínfima das relações jurídicas supõe, necessáriamente, a unidade social do gênero humano ou, seja, um estilo

(12) Lacerda de Almeida, Direito das Cousas, t. I, Rio de Janeiro, 1908, § 4, p. 37 
de convivio em que, para tornar-se sujeito de relação tal, ao homem baste a sua humanidade. As demais conotações sociais do homem, a nacionalidade, o vúnculo político, a solidariedade grupal, os laços de familia super-ajuntam-se àquela condição essencial, - a condição humana. Estado, grupo, família são divisões e sub-divisões da sociedade universal, necessita como condição "sine qua" pela relação jurídica. São frações da unidade social universal, como o cidadão, o membro, o grupo, o parente são aspectos fracionários do mesmo homem. Certo, cada uma dessas frações é única, na medida em que participa da incomunicabilidade da pessoa (13), porque de pessoas se compõe; e essa unicidade, particularmente no que concerne ao Estado, tende a obscurecer-lhes a verdadeira natureza, como frações. A unidade da sociedade universal patenteia-se-nos, entretanto, isso não obstante. Suarez disse, excelentemente: "humanum genus quantumvis in varios populos et regna divisum, semper habet aliquam unitatem" (14).

Uma nação que se revolte contra a humanidade, um grupo social ou uma família que se insurja contra a Nação, e a ordem jurídica, nessa Nação, nêsse grupo, nessa familia, entra a deformar-se como liquido que, de um vaso, se derrama. o nacional-socialismo alemão e o fascismo italiano são exemplos, ainđđa recentes, dessa inevitável deformação. O social, nessa sua maỉs ampla acepção, é condição do jurídico.

A relação juridica, na verdade, supõe, necessáriamente, o fato social. Sem dúvida, os valores morais, para afirmar-se, dispensam os fatos sociais; mas os fatos sociais sómente podem dizer-se fatos sociais enquanto qualificáveis segundo os valores morais. A proposição de DuRKHeIm ("faites evanouir toute vie sociale et la vie morale s'evanouit du même coup")

(13) Ric. DE S. VIctore, De Trinitate, lib. IV, cap. XVIII e

(14) De Legibus, lib. II, cap. XIX, n. 9

XXIII; cf. S. TH., De Potent, q. 9, art. 3, ad. XII 
(15) é verdadeira às avessas. O homem tem uma vida interior moral e no intercâmbio do convívio social, como PAUL Bureau agudamente observa, "tout sa vie intérieure est engagée dans le moindre de ses actes" (1).

A nota do social domina os demais elementos do fato jurídico. O negócio jurídico é a expressão objetiva da yontade como ação ("actio") através de um comportamento social. A rigor, sómente a "actio" pertence à estrutura ontológica da relação. $O$ remanescente do negócio jurídico é, de si mesmo, um estilo de intercâmbio social, apenas. $O$ objeto do contrato não mais encerra, igualmente, do que um comportamento social: "dare, facere, praestare".

\section{III}

O fato jurídico, assim conceituado, é condição da relação juridica. Fundamento ou causa desta é a disposição do sujeito em face do termo, como antecedente ou consequente de uma ação ("actio").

A ação é o suporte ontológico da valorização mora] da relação; indica a participação essencial da vontade na relação jurídica, e nas transmutações desta, por isso que, se pode conceber-se, nas cousas criadas, ação sem vontade, não se concebe, no entanto, vontade sem ação.

Santo Tomás distingue nítidamente duas formas de fundamentação da relação: "vel secundum virtutem activam et passivam, secundum quod una res ab alia recipit vel alteri confert aliquid" (17); (vel) "super id quod, in

(15) De la Division du Travail Social, Paris, 1902, p. 395

(16) Introduction à la Methode Sociologique, Paris, 1926, p. 146 e 147

(17) Com. in V Lib. Metaphys, lect. XVII, init. 
agente ex actione relinquitur, sive sit dispositio, sive habitus, sive aliquod jus" (18).

A primeira forma de fundamentação da relação jurídica corresponde ao que a Ciência Iurídica nos designa como autonomia da vontade. A vontade como tal, "virtus activa", indeterminada, então, quanto ao seu conteúdo, fixará, mais de uma vez, até o indefinido, se não se vincular diversamente, as virtualidades da dependência do termo em face do sujeito da relação. Assim, o domínio é definido como "o direito real que vincula e legalmente submete ao poder absoluto da nossa vontade cousa corpórea, na substância, acidentes e acessórios (19).

A segunda forma de fundamentação da relação jurídica implica a determinação prévia e exaustiva, pela norma jurídica, do conteúdo que o ato de vontade terá, ao ser praticado, fundando-se, nêsse caso, a relação "super id quod in agente ex actione relinquitur". Correspondem-lhe, na classificação da Ciência Jurídica, as relações jurídicas, vinculadas, não a uma vontade, mas a uma finalidade (20). Nessa espécie de relação, a vontade do sujeito supõe-se atual ("in actu"), e predeterminada em seu conteúdo, pela finalidade que a norma jurídica lha prescreve. A mulher, que aceita a "datio dotis", submete-se à finalidade que a lei prescreve ao dote: e essa finalidade delimita a dependência em que lhe ficam os bens dotais, fixando, de antemão as virtualidades dessa dependência do termo em face do sujeito da relação.

(18) Com. in III Lib. Sentent., dist. VIII, q. I, art. 5, c.

(19) Lafayette, Direito das Cousas, Rio de Janeiro, 1877, t. I, $\S 24$, p. 74 .

(20) Cf. Ruy Cinne Lima, A Relação Jurídica no Direito Administrativo, Pôrto Alegre, 1952. 


\section{IV}

Relação e ordem são, ontológicamente, termos conversiveis, um ao outro. Mas, a ordem pode ser entendida normológicamente, não ontológicamente, - como sistema de normas, e não como sistema de relações.

$\mathrm{Na}$ verdade, chama-se, geralmente, ordem jurídica ao conjunto das normas, em que se enuncia o princípio de ordem, segundo o qual as relações jurídicas vêm a constituir-se, e os corolários, desenvolvimentos e aplicações desse princípio sumo.

Tal pode ser, de feito, a exata noção da ordem jurídica, se a consideramos, porém, estáticamente, no plano deontológico. Nessa acepção, a ordem jurídica é simplesmente o arqúetipo normológico da ordem juridica, dinâmicamente considerada, no plano ontológico.

Não é menor, certamente, a realidade da norma jurídica do que a da relação jurídica, "ens debilissimum". Mas a norma não é relação; antes da relação se faz a norma: "ex jure quod est regula fiat" (21).

Considerada, dinâmicamente, no plano ontológico, a ordem jurídica é, à sua vez, antes organização do que ordenação; antes instrumento ("organum") do que resultado: é a "ordo partium ad invicem", que necessita como causa a “ordo ad finem" (22), e não sómente, de algum modo, como causa eficiente, senão como causa final.

A organização é, destarte, nota especial da ordem jurídica em seu aspecto dinâmico. Comunidade internacional, Estado, grupo, família, propriedade, negócio jurídico são formas de organização, formas instrumentais, para a persecução da finalidade do homem, como tal. São relações, pelas quais se consociam, na persecuçâo

(21) Dig., lib. L., tit. XVII, de regulis juris, fr. 1

(22) S. Tн., De Verit., q. 5, art. 3, c. 
dessa finalidade, o homem e as cousas, ou a ação de um homem à ação ou paciência de outro. Certo, o homem, sómente, é comensurável ao seu próprio fim. As relações que assim se estabelecem, ordenam-se a fins intermédios mas nem por isso deixam de participar da ordem ao fim último: "non solum sicut ordinatum ad aliud, sed sicut ad quod aliud ordinatur" (23).

Na escala dos fins intermédios, entretanto, o homem, não raro, é substituido e subrogado pela relação, graças à qual pode persegui-los e alcança-los. $O$ proprietário não é o homem, apenas; mas o homem e a cousa, de que é dono. $O$ esposo supõe a esposa; o cidadão, o Estado, o Estado, a comunidade internacional. Essa subrogação atinge o máximo, quando se atribui à relação mesma a condição de pessoa, e surge, assim, a pessoa jurídica.

o máximo na subrogação coincide, a seu turno, com o máximo na organização. A pessoa jurídica é, pode dizer-se, a extrinsecação da organização, com respeito à ordem e à relação.

Define-se a pessoa jurídica como a relação existente entre duas ou mais pessoas, para a unificação e, frequentemente, para a perpetuação em unidade, quanto a ações determinadas, das virtualidades insitas na capasidade de agir de cada uma. Ações há que essencialmente requerem o concurso ativo de uma pluralidade de agentes, a união acidental de múltiplas capacidades de agir. Em tal caso, malgrado a pluralidade dos agentes, a unidade da ação é um dado ontológico. A unidade da ação, efeito da relação, constitui, nesse caso, - é de reconhecer-se o principio, pelo qual se produz a ação ("principium quo"), não, sem dúvida, "per modum agentis", - sede per modum exercitii” (24).

(23) S. TH. de Verit., q. 5, art. 4, c.

(24) Urraburu, Institutiones Philosophicae, t. II, Ontologia. Vallisoleti, 1891, disp. 7, cap. II, art. 3. n.o 397, p. 1146 
Surgida a pessoa juridica, - entidade real, enquanto relação real, o fato jurídico que lhe é condição, enquanto relação, transforma-se afeiçoa-se, à semelhança do homem, de que a pessoa jurídica vem a tomar o lugar.

$\mathrm{O}$ pensamento originário das concepções organicistas da pessoa jurídica não é tão extravagante, como sói correntemente dizer-se. Porque a relação é ordem, e a ordem é organização, a pessoa jurídica, que é relação, ha de ser "eo ipso" organização também. Que organização supor-se, de oưtro lado, ao fato jurlidico, ordenado pela relação personificada, senão uma organização análoga à do homem, de que a relação passa a ocupar o lugar?

A extravagância da concepção organicista é antes história, do que lógica. A doutrina da pessoa jurídica repousa, certamente, sôbre uma analogia com o homem, mas uma analogia não dirétamente estabelecida, senão de torna-viagem. Vem-nos a doutrina da pessoa juridica, ao influxo do pensamento greco-cristão, da doutrina teológica das três Pessoas Divinas (25), pela qual, a seu turno, o conhecimento da realidade divina nos é ministrado, em analogia com o nosso conhecimento do homem. A analogia direta das concepções organicistas extravaga, pois, do processo histórico de elaboração dù doutrina da pessoa jurídica, precisamente pelo que tem de direto e imediato.

A organização do fato jurídico, condicionador da relação que se personifica, obedece, claramente, ainda hoje, ao método teológico das apropriações. Consiste a apropriação em atribuir-se, de modo especial, a uma pessoa Divina, atributo essencial ou operação, comumı às tres Pessoas da Divina Trindade (26). Da apropriação

(25) Cf. Bonfante, Scritti Giuridici Varii, t. HI, Torino, 1926. nota, p. 472

(26) Mons, Institutiones Theologiae Dogmaticae, t. I, Petropoli, 1941, n. ${ }^{\circ} 488$, p. 317 
teológica, provém-nos inequívocamente o conceito jurídico da competência; da competência, a noção jurídica do órgão.

Da Teologia, consequentemente, pode dizer-se, procedem a doutrina da pessoa jurídica e a forma de organização do fato jurídico, que lhe condiciona a existência e a vigência como relação. A não ser, realmente, como alusão teológica, as noções de competência e de órgão não poderiam ter encontrado lugar na estrutura da pessoa jurídica.

Nesta, a união de ação, o compósito dinâmico, meramente acidental, repelem a idéia de unidade essencial. Em Deus, a essência é uma só, embora três as Pessoas Divinas; e a unidade essencial, ela só, é que legitima a apropriação -- essa mesma unidade essencial que falta, por completo, no fato jurídico, condicionador da relação personificada. Mas o transporte, da Teologia ao Direito, do conceito de apropriação se verificou, apesar da contradição nas essências; e a pessoa jurídica passou a ter, e os tem, ainda hoje, orgãos e competências.

\section{V}

$\mathrm{Na}$ ordem jurídica, a pessoa jurídica, por excêlencia, é o Estado. No Estado se incorpora o poder de dirigir e governar, a coletividade social, unida pelo mesmo vínculo político. E como no poder de dirigir e governar se inclui o de editar a lei, a relação jurídica, personificada no Estado, passa, de tal sorte, à condição de fonte formal de normas jurídicas positivas. A ordem jurídica, estáticamente considerada, na parte em que se compõe de leis humanas, positivas, vem a ter, portanto, como razão formal, a mesma ordem jurídica, dinâmicamente considerada ou seja, uma, dentre as relações juridicas, que lhe toca regular. Traduz-se e explica-se, por êsse modo, o circulo 
vicioso do direito positivo, que Brinz denunciara, ao sinalar que o direito dispõe, antes de tudo, acêrca de si mesmo (27).

Relação jurídica, mais tênue, ainda, porque não personificada, têmo-la como fonte formal das normas jurídicas positivas da comunidade internacional. Dimanam estas de tratados e costumes ou, seja, de relações jurídicas voluntárias entre as Nações (28).

Acima dêsse direito positivo, interno e internacional, há, porém, e teria de haver, um sistema de normas jurídicas, capaz de responder à realidade ontológica da relação jurídica. A êsse sistema de normas jurídicas chama-se-lhe direito natural. As suas normas promulgam-se nas consciência individuais (29), e são universais (30) e necessárias (31).

Aqui, finalmente, enquanto respeita à ordem jurídica, estáticamente considerada, ísto é, havida como conjunto de normas, o homem chega a encontrar-se consigo mesmo. A lei natural está inscrita em seu coração (32); e dessa lei natural se derivam, pelo conteudo, tôdas as leis humanas positivas, verdadeiramente tais (33).

Frente a frente, consigo mesmo, ao homem se depara, enfim, a razão última da ordem jurídica, no duplo aspecto, estático e dinâmico, de norma e relação, entrelaçados no direito positivo, como por uma reciproca petição de prin-

(27) Cf. StAMmLeR, Wesen des Rechtes under Rechtswissenschaft, Systematische Rechtswissenschaft, herausgegeben von Paul Hinneberg, Leipzig - Berlin, 1913, p. 32.

(28) WolfF, Jus Gentium Meth. Ccient. Pertract. Proleg., § 25 "Quamobrem cum facile pateat Jus Gentium voluntarium pactitium et consuetudinarium a voluntate gentium trahere, jus istuid omne Jus Gentinm positivum est."

(29) S. Tн. Sum. Theol. I, II, q. 90, art. 4, ad I.

(30) S. TH. Sum Theol. I, II, q. 94, art. 4, c.

(31) S. TH. Sum. Theol. I, II, q. 97, art. III

(32) S. Paulo, Rom. II, 15

(33) S. Tн. Sum. Theol. I, I, q. 95, art. 2, c. 
cipio. Descobre-se-lhe, afinal, o principio que os dois aspectos da ordem jurídica, em vão, pediam um ao outro, dentro nos lindes das leis humanas.

Deus que criou o homem, imprimiu-lhe, também, no ser a inclinação natural à justiça, e promulgou-lhe no coração a lei. Criação e legislação, enquanto à criatura racional, são atos que não se podem dissociar. "Naturale jus", - lê-se no prefácio ao "Decretum", _ "naturale jus coepit ab exordio naturalis creaturae".

A Criação, - a palavra primeira, - é, pois, aqui a palave'a final. 